\title{
Serum Neutrophil Gelatinase-Associated Lipocalin - A Sensitive Novel Marker of Renal Impairment in Liver Cirrhosis?
}

\author{
A.L. Gerbes ${ }^{a} \quad$ A. Benesic ${ }^{a} \quad$ M. Vogeser ${ }^{b} \quad$ A. Kragc, ${ }^{c}$ F. Bendtsen ${ }^{c, d} \quad$ S. Møller \\ a Liver Center Munich, Department of Internal Medicine II, and ${ }^{b}$ Institute for Clinical Chemistry, University Hospital \\ Grosshadern, LMU Muenchen, Munich, Germany; Departments of ${ }^{\mathrm{C} C l i n i c a l ~ P h y s i o l o g y ~ a n d ~ N u c l e a r ~ M e d i c i n e, ~ a n d ~}$ \\ ${ }^{\mathrm{d}}$ Medical Gastroenterology, Hvidovre Hospital, University of Copenhagen, Hvidovre, Denmark
}

Dear Sir,

Renal dysfunction is a frequent and clinically relevant problem in patients with cirrhosis of the liver [1]. While acute renal failure as in hepatorenal syndrome type 1 is characterized by a rapid increase of serum creatinine (Crea) concentration [2], chronic renal dysfunction may be difficult to detect. For determination of the glomerular filtration rate (GFR), the use of clearance techniques is the gold standard. These techniques, however, are cumbersome and not suitable for clinical routine. Serum Crea is simple and easy to determine and therefore widely used per se or in Crea-based formulae such as MDRD (Modification of Diet in Renal Disease formula, using serum Crea, age and gender). Unfortunately, Crea is not a precise parameter of renal function in cirrhosis [3]. The overestimation of GFR by serum Crea and Crea-based equations is striking, particularly in decompensated patients with cirrhosis and normal or slightly increased Crea. Clinically it seems most important to identify renal dysfunction in these patients at an early stage before development of a hepatorenal syndrome denoting a poor prognosis. Therefore, other serum parameters such as cystatin $\mathrm{C}$ have been proposed to reflect renal function in cirrhosis [4] but have not been generally accepted yet.
Recently, neutrophil gelatinase-associated lipocalin (NGAL) has been introduced as a sensitive and early marker of acute kidney injury [5]. NGAL in cirrhosis and chronic renal failure has not been investigated so far. We have therefore analyzed NGAL and GFR in patients with decompensated cirrhosis and normal or moderately increased Crea.

Twenty-two patients with cirrhosis and ascites and stable Crea $<1.5 \mathrm{mg} / \mathrm{dl}$ had GFR measured by the ${ }^{51} \mathrm{Cr}$-EDTA technique [6]. The study was approved by the regional ethics committee, registered

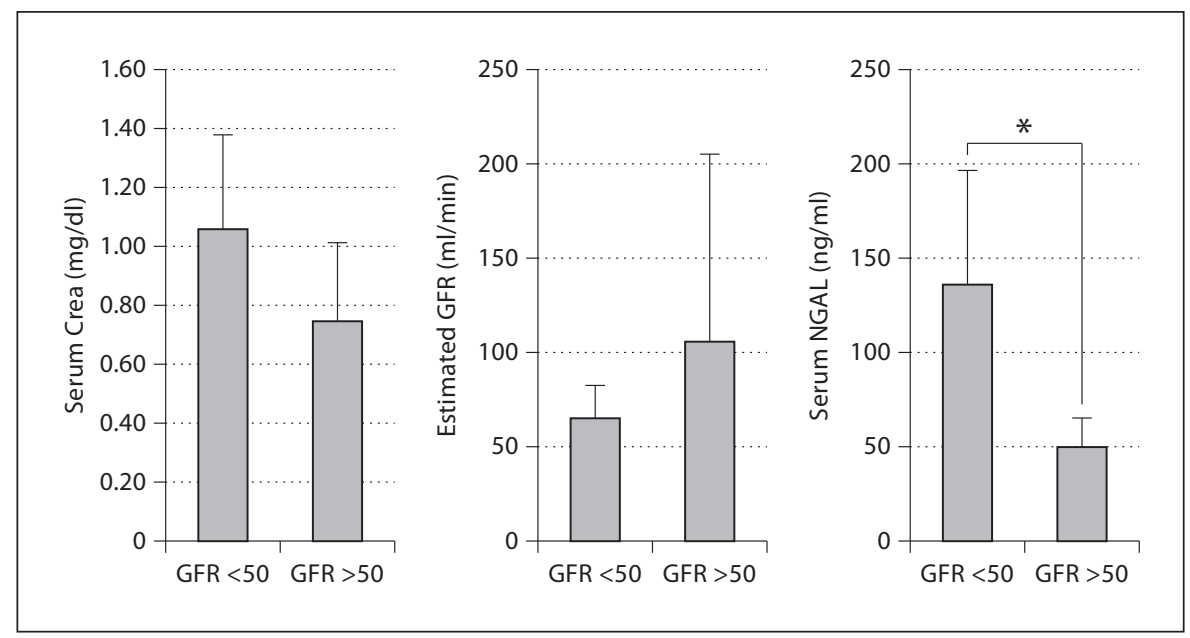

Fig. 1. Serum Crea, estimated GFR as calculated by MDRD4 formula and serum NGAL in patients with cirrhosis and GFR $<50$ or $>50 \mathrm{ml} / \mathrm{min}$. Only serum NGAL is significantly different between both groups $\left(^{*}\right)$.

\section{KARGER}

Fax +41613061234 E-Mail karger@karger.ch www.karger.com www.karger.com/dig
Andreas Benesic, MD

Liver Center Munich, Department of Internal Medicine II

University Hospital Grosshadern, LMU Muenchen

Marcioninistrasse 15, DE-81377 Munich (Germany)

Tel. +49897095 3176, E-Mail andreas.benesic@med.uni-muenchen.de 
(NCT00115947) and inspected by the Danish Medicines Agency. Using sandwich-ELISA technique (Bioporto, Gentofte, Denmark), NGAL in serum and urine was determined. A GFR of $50 \mathrm{ml} /$ min was considered as a clinically significant cutoff point. Results are expressed as means and standard deviation. Statistical analyses were performed with unpaired $t$ tests.

\section{References}

1 Gerbes AL (ed): Ascites, Hyponatremia and Hepatorenal Syndrome: Progress in Treatment. Front Gastrointest Res. Basel, Karger, 2011, vol 28.

-2 Salerno F, Gerbes A, Ginès P, Wong F, Arroyo $\mathrm{V}$ : Diagnosis, prevention and treatment of hepatorenal syndrome in cirrhosis. Gut 2007;56:1310-1318.
GFR $<50$ or $>50 \mathrm{ml} / \mathrm{min}$ was found in 6 and 16 patients, respectively $(29 \pm 10 \mathrm{vs}$. $69 \pm 15 \mathrm{ml} / \mathrm{min} ; \mathrm{p}<0.01)$. These two groups exhibited Crea $(1.1 \pm 0.3$ vs. $0.8 \pm$ $0.2 \mathrm{mg} / \mathrm{dl}$; n.s.), estimated GFR (MDRD4) $(65 \pm 17$ vs. $106 \pm 34 \mathrm{ml} / \mathrm{min}$; n.s. $)$ and serum NGAL $(136 \pm 61$ vs. $50 \pm 15 \mathrm{ng} / \mathrm{ml}$; $\mathrm{p}<0.01$ ) as shown in figure 1 . Urinary NGAL was similar in both groups. Five of 6 patients with GFR $<50 \mathrm{ml} / \mathrm{min}$ had
NGAL $>100 \mathrm{ng} / \mathrm{ml}$. AUC analysis showed NGAL with a cutoff of $100 \mathrm{ng} / \mathrm{ml}$ superior $(\mathrm{p}<0.05)$ to Crea $(0.98 ; 0.96-1.00$ vs. 0.79 ; $0.66-0.92)$ in identifying patients with a GFR $<50 \mathrm{ml} / \mathrm{min}$.

These data in a small but well-characterized group of patients indicate that serum NGAL could be a sensitive novel marker of low GFR in cirrhosis. Further evaluation seems warranted.
3 Gerbes AL, Gülberg V: Letter. Renal failure in cirrhosis. N Engl J Med 2010;362:79-80.

-4 Gerbes AL, Gülberg V, Bilzer M, Vogeser M: Evaluation of serum cystatin C concentration as a marker of renal function in patients with cirrhosis of the liver. Gut 2002;50:106110.
5 Devaraian P: Neutrophil gelatinase-associated lipocalin: a troponin-like biomarker for human acute kidney injury. Nephrology 2010;15:419-428.

-6 Krag A, Møller S, Henriksen JH, HolsteinRathlou NH, Larsen FS, Bendtsen F: Terlipressin improves renal function in patients with cirrhosis and ascites without hepatorenal syndrome. Hepatology 2007;46:18631871. 